\title{
Testing for news and noise in non-stationary time series subject to multiple historical revisions
}

Citation for published version (APA):

Hecq, A. W., Jacobs, J. P. A. M., \& Stamatogiannis, M. (2016). Testing for news and noise in nonstationary time series subject to multiple historical revisions. Maastricht University, Graduate School of Business and Economics. GSBE Research Memoranda No. 004 https://doi.org/10.26481/umagsb.2016004

Document status and date:

Published: 01/01/2016

DOI:

10.26481/umagsb.2016004

Document Version:

Publisher's PDF, also known as Version of record

\section{Please check the document version of this publication:}

- A submitted manuscript is the version of the article upon submission and before peer-review. There can be important differences between the submitted version and the official published version of record. People interested in the research are advised to contact the author for the final version of the publication, or visit the DOI to the publisher's website.

- The final author version and the galley proof are versions of the publication after peer review.

- The final published version features the final layout of the paper including the volume, issue and page numbers.

Link to publication

\footnotetext{
General rights rights.

- You may freely distribute the URL identifying the publication in the public portal. please follow below link for the End User Agreement:

www.umlib.nl/taverne-license

Take down policy

If you believe that this document breaches copyright please contact us at:

repository@maastrichtuniversity.nl

providing details and we will investigate your claim.
}

Copyright and moral rights for the publications made accessible in the public portal are retained by the authors and/or other copyright owners and it is a condition of accessing publications that users recognise and abide by the legal requirements associated with these

- Users may download and print one copy of any publication from the public portal for the purpose of private study or research.

- You may not further distribute the material or use it for any profit-making activity or commercial gain

If the publication is distributed under the terms of Article $25 \mathrm{fa}$ of the Dutch Copyright Act, indicated by the "Taverne" license above, 
Alain Hecq, Jan P.A.M. Jacobs, Michalis P. Stamatogiannis

Testing for news and noise in non-stationary time series subject to multiple historical revisions

$\mathrm{RM} / 16 / 004$

\section{GSBE}

Maastricht University School of Business and Economics

Graduate School of Business and Economics

P.O Box 616

NL-6200 MD Maastricht

The Netherlands 


\title{
TESTING FOR NEWS AND NOISE IN NON-STATIONARY TIME SERIES SUBJECT TO MULTIPLE HISTORICAL REVISIONS
}

\author{
Alain Hecq \\ Maastricht University \\ [a.hecq@maastrichtuniversity.nl] \\ Jan P.A.M.Jacobs \\ University of Groningen, University of Tasmania, CAMA and CIRANO \\ [j.p.a.m.jacobs@rug.nl]

\section{Michalis P. Stamatogiannis} \\ University of Liverpool \\ [m.stamatogiannis@liverpool.ac.uk]
}

This version: January 2016

\begin{abstract}
Before being considered definitive, data currently produced by statistical agencies undergo a recurrent revision process resulting in different releases of the same phenomenon. The collection of all these vintages is referred to as a real-time data set. Economists and econometricians have realized the importance of this type of information for economic modeling and forecasting.

This paper focuses on testing non-stationary data for forecastability, i.e., whether revisions reduce noise or are news. To deal with historical revisions which affect the whole vintage of time series due to redefinitions, methodological innovations etc., we employ the recently developed impulse indicator saturation approach, which involves potentially adding an indicator dummy for each observation to the model. We illustrate our procedures with the U.S. Real Gross National Product series from ALFRED and find that revisions to this series neither reduce noise nor can be considered as news.
\end{abstract}

Keywords: Data revision, Non-Stationary Data, News-Noise Tests, Structural Breaks

JEL-code: C32, C82, E01 


\section{Introduction}

Before being considered definitive, data currently produced by statistical agencies typically undergo a recurrent revision process resulting in different releases of the same phenomenon. The collection of all these vintages is referred to as a real-time data set. In the recent past, economists and econometricians have come to realize the importance of this type of information for economic modeling, forecasting and policy formulation. Consequently there exists a growing interest for investigating this type of data (see inter alia Croushore and Stark, 2001, Orphanides and van Norden, 2002, and Croushore, 2011a, 2011b).

Several aspects of real-time data can be investigated: (i) structural or trend breaks (see Jacobs and van Norden (2015) for a summary of the reliability of productivity growth rate trends); (ii) forecastability, i.e., whether revisions reduce noise or are news (the literature is briefly reviewed in Section 3.1); (iii) historical revisions, which affect the whole vintage of time series due to redefinitions, methodological innovations, etc., make testing difficult. The standard approach to dealing with historical revisions is either to employ growth rates to mitigate the effects of historical revisions, or to 'clean' the series in an attempt to get rid of the effects of historical revisions. The former approach has been criticized by Knetsch and Reimers (2009). Götz, Hecq and Urbain (2016) illustrate that growth rates can also be affected by large revisions.

Whereas the tests and the procedures to deal with historical revisions are welldocumented for stationary time series (e.g., using Mincer-Zarnowitz type tests), the situation is less clear for non-stationary time series. The paper aims at filling this void, building upon Hecq and Jacobs (2009). We focus on testing forecastability for non-stationary real-time data, putting data releases in vector-error correcting forms (VECMs hereafter). To deal with forecastability under historical revisions at unknown dates, we estimate VECMs using an automatic modelling method for selecting conditional mean parameters (the Autometrics algorithm, see Hendry and 
Doornik, 2014) together with the Impulse Indicator Saturation approach (IIS hereafter, see e.g., Hendry and Santos, 2005). Briefly, IIS involves adding an indicator dummy ${ }^{1}$ for potentially each observation to the model and hence is able to determine a parsimonious model that fits model requirements in terms of misspecifications. We illustrate our procedures with the U.S. Real Gross National Product (real GNP hereafter) series from ALFRED and find that, in general, revisions neither reduce noise nor can be considered as noise. Conclusions would have been different without the IIS approach.

An alternative strategy to the IIS algorithm consists of introducing dummy variables for each revision because historical revisions are often well documented and recorded. This operation is less obvious than one might think at first glance and can be very tedious and time consuming for an external researcher who does not have complete information on thousands of economic variables for different countries. While one can easily find the description of the modifications for the main aggregates for the U.S. or the European Union for instance, this task is much more demanding when the information about data revisions is for instance not in English or not available online on national statistical agencies websites. Using IIS helps in investigating those time series within a few seconds. Secondly, one can also notice that the date at which vintages are released might differ from the date at which the series has been theoretically modified. As an example, books may describe that there is a new definition of an economic indicator in January but the series published on, say the 10th of January, still applies the old definition. It might be for this latter example that a second vintage is available at the end of the month such that we observe multiple vintages for one particular month, a situation that adds difficulties for the researcher. Third, IIS can also capture smaller revisions (e.g., annual or seasonal revisions due to e.g., the change of seasonal factors) that would have ignored based on historical revisions only. Finally, many real-time databases

\footnotetext{
${ }^{1}$ We leave for further research the use of additional step dummies in the IIS framework.
} 
have been build manually, either by merging files or using manpower for scanning or copying figures from statistical reports. Those operations can also introduce errors.

The remainder of the paper is structured as follows. After a brief introduction of data revisions and notations in Section 2, Section 3 describes news-noise tests for stationary and non-stationary real-time data as well as the intuition underlying the IIS approach. Section 4 illustrates our procedure with the U.S. Real National Product series. Section 5 concludes.

\section{Data revisions and notation}

Real-time data are typically displayed in the form of a real-time data trapezoid as in Figure 1. We move to later vintages as we move across columns from left to right and we move to later points in time when we move down the rows. Note that the frequency of vintages needs not necessarily correspond to the unit of observation; for example, in our illustration below the statistical agency publishes monthly vintages of quarterly observations. In this paper we investigate the releases, namely the diagonals of the data trapezoid. We use the following notation: superscripts refer to releases $i=1, \ldots, v$, while subscripts refer to periods; $y_{t}^{1}$ denotes the first release for variable $y$ in period $t$, whereas the sequence $\left\{y_{t}^{1}\right\}_{t=1}^{T}$ or simply $y_{t}^{1}, t=1, \ldots, T$ refers to as the whole time series for the first release, namely the first diagonal in Figure 1.

Figure 1: The real-time data trapezoid

$$
\left[\begin{array}{ccccc}
y_{1}^{1} & \ldots & y_{1}^{i} & \ldots & y_{1}^{v} \\
& \ddots & \vdots & \ddots & \vdots \\
& & y_{t-l}^{1} & \ldots & y_{t-l}^{i} \\
& & & \ddots & \vdots \\
& & & & y_{t}^{1}
\end{array}\right]
$$


Data revisions may be conveniently categorized into three types:

1. initial revisions in the first few vintages,

2. annual (seasonal) revisions due to updated seasonal factors and the confrontation of quarterly with annual information, and

3. historical or comprehensive revisions, related to changes in statistical methodology, etc.

The distinction of revisions into these types requires careful handling of the realtime data and in many cases direct access to the officials of the statistical agency. Initial and seasonal revisions are regular and recurring, and can in principle be modeled and forecast. As an example, Eurostat releases its first estimate of e.g., real GDP 45 days after the end of the corresponding quarter (flash estimate), the next release is 15 days later. Historical revisions are much more difficult to handle. Redefinitions like changes of base years do not cause many difficulties, however changes in definitions changes do.

Whatever their origins, data revisions imply the existence of measurement errors. The modeling of measurement errors has two main traditions that are surveyed in the next section.

\section{Method}

\subsection{News-noise tests}

\section{Stationary data}

The older tradition, which is still widespread among statisticians, is that measurement errors should be thought of as noise. Data are measured with errors which are orthogonal to true values $\left(\widetilde{y}_{t}\right)$. This implies for a stationary time series $y_{t}$ that for 
all releases $i$

$$
y_{t}^{i}=\widetilde{y}_{t}+\zeta_{t}^{i}, \quad \operatorname{cov}\left(\widetilde{y}_{t}, \zeta_{t}^{i}\right)=0
$$

One implication of this is that revisions will generally be forecastable by taking weighted averages of previous releases. To test whether measurement errors reduce noise, the Mincer-Zarnowitz (1969) test can be used, which regresses the revision $y_{t}^{C V}-y_{t}^{i}$ on a constant and the most recent, i.e., the current (last observed column) vintage $y_{t}^{C V}$, taken as measure of the unobserved true value $\widetilde{y}_{t}$

$$
y_{t}^{C V}-y_{t}^{i}=\delta_{1}+\beta_{1} y_{t}^{C V}+\zeta_{t}^{i}
$$

The null hypothesis that measurement errors are independent of true values $\left(\delta_{1}=\right.$ $\left.0, \beta_{1}=0\right)$ may be tested with a Wald test; since the errors may suffer from heteroskedasticity and autocorrelation, robust HAC standard errors are typically used.

The "newer" tradition, motivated by Mankiw, Runkle and Shapiro (1984), Mankiw and Shapiro (1986) and de Jong (1987), describes measurement errors as news. ${ }^{2}$ News errors imply that published data are optimal forecasts, so revisions are orthogonal to earlier releases and are not forecastable. More precisely,

$$
y_{t}^{C V}=y_{t}^{i}+\nu_{t}^{i}, \quad \operatorname{cov}\left(y_{t}^{i}, \nu_{t}^{i}\right)=0
$$

The analogous test of the "news" model regresses the revision $\left(y_{t}^{C V}-y_{t}^{i}\right)$ on a constant and the $i$ th-release

$$
y_{t}^{C V}-y_{t}^{i}=\delta_{2}+\beta_{2} y_{t}^{i}+\nu_{t}^{i}
$$

A similar null hypothesis $\left(\delta_{2}=0, \beta_{2}=0\right)$ now tests whether data revisions are predictable. The two null hypotheses are mutually exclusive but they are not collec-

\footnotetext{
${ }^{2}$ See also the more recent contributions of Faust, Rogers and Wright (2005), Swanson and van Dijk (2006) and Aruoba (2008). More references are in Jacobs and van Norden (2011).
} 
tively exhaustive, i.e., we may be able to reject both hypotheses, particularly when the constant in both test equations differs from zero (see Aruoba, 2008, Appendix A.2). The main conclusion of the empirical literature on characteristics of real-time data is that macroeconomic time series are in principle not well-behaved. Revisions can be substantial and reduce noise or add news at different horizons.

An alternative way to test for news and noise is to estimate the Jacobs and van Norden (2011) data revision model, a state-space form in which measurement errors are decomposed into news and noise with the possibility of spillovers. Recently, Clements and Galvão (2013) extended the Jacobs and van Norden (2011) framework by allowing for revision bias. The alternative state-space forms of Cunningham et al. (2012) and Kishor and Koenig (2012) should in principle be able to do the same. Fixler and Nalewaik (2009) propose an alternative test, whose properties still have to be explored. Finally, the multi-period survey approach of Patton and Timmermann belongs in this category too.

\section{Non-stationary data}

Testing measurement errors in case of non-stationary variables is more complicated even when a single time series, like gross national product, is considered. Indeed, the existence of cointegration between different releases hampers the application of Mincer-Zarnowitz tests explained above for two reasons. First, the presence of cointegration implies that there exists a long-run relationship between different releases and hence news/noise tests would be subject to the usual omitted variable problem if we estimate (4) or (2) on the growth rates of time series only. Second, assuming that we correctly account for cointegrated I(1) series in VECM systems, the issue still remains that we cannot establish the direction of causality, i.e., whether the first release is explained by the last release, or the other way around. However, weak exogeneity tests in cointegrated systems (see Urbain, 1992, 1995) can be helpful here. 
Cointegration between time series of different releases, or intra-variable cointegration, can be modeled in two ways. ${ }^{3}$ The approach most frequently adopted in the literature looks at releases on an observation basis, for example first and second releases of variable $y_{t}$ observed on $T+1$ data points. The Observation Balanced System (OBS hereafter) tests for cointegration between series $y_{t}^{1}$ and $y_{t}^{2}, t=1, \ldots, T$. Superscripts denote respectively the first and the second released diagonals as visualized in Figure 2. The red box emphasizes that the most recent observation in period $T+1$ is excluded from the analysis. Note also that in this description we explicitly consider that publication lags do not exist. We also prefer to denote the diagonal releases while making an explicit reference of the release number instead of adding another $t$ component in the superscript of $y$. It must be understood though that we take the first two releases as a convenient explanatory example but that we investigate the relationships between several releases in this paper. ${ }^{4}$

Figure 2: Observation Balanced System (OBS)

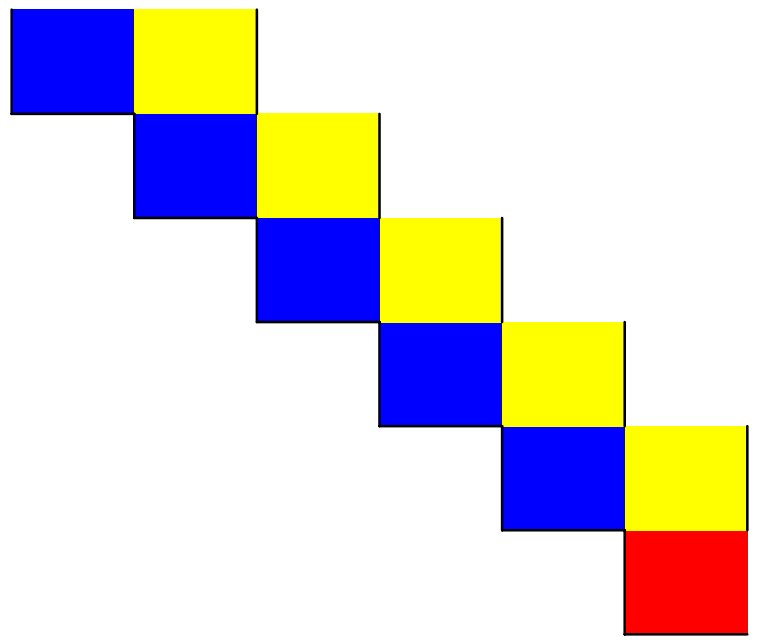

The alternative approach compares the releases on a vintage basis, i.e., the two most recent observations of vintages. In the Vintage Balanced System (VBS hereafter) cointegration between $y_{t+1}^{1}$ and $y_{t}^{2}, t=1, \ldots, T$, is considered, see Figure 3.

\footnotetext{
${ }^{3}$ The remainder of this section draws upon Hecq and Jacobs (2009).

${ }^{4}$ We leave the multivariate investigation of the whole set of releases for further investigations. In this paper we only look at pairwise tests.
} 
Patterson (2000) is a typical example of the OBS approach, whereas Garratt et al. (2008, 2009) adopt VBS.

Figure 3: Vintage Balanced System (VBS)

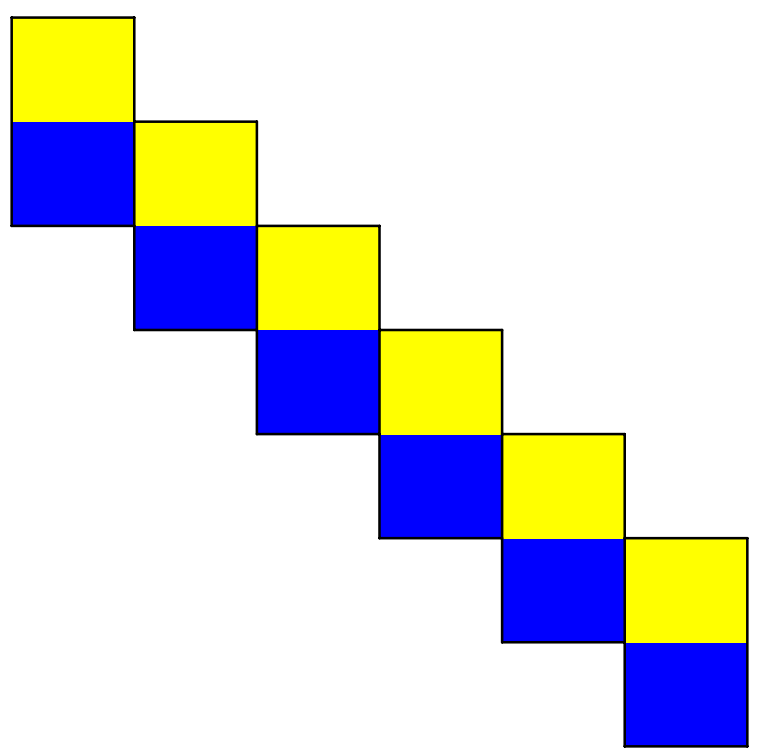

Note that, if $y_{t}$ is integrated of order one, OBS and VBS are equivalent in terms of the cointegration property because of the identity

$$
y_{t}^{1}-y_{t}^{2} \equiv\left(y_{t}^{1}-y_{t+1}^{1}\right)+\left(y_{t+1}^{1}-y_{t}^{2}\right)
$$

and such that $\left(y_{t}^{1}-y_{t+1}^{1}\right)$ is $\mathrm{I}(0)$.

Weak exogeneity tests in OBS can reveal whether revisions reduce noise or add news. By exploiting the Gonzalo-Granger (1995) permanent-transitory decomposition, Patterson $(2002,2003)$ shows that if the final release is weakly exogenous for the parameters of the system then measurement errors in OBS cointegration are noise. For an alternative way to see this consider a bivariate VECM of order one in first differences for OBS releases as

$$
\left(\begin{array}{c}
\Delta y_{t}^{2} \\
\Delta y_{t}^{1}
\end{array}\right)=\alpha \beta^{\prime}\left(\begin{array}{c}
y_{t-1}^{2} \\
y_{t-1}^{1}
\end{array}\right)+\left(\begin{array}{c}
\Phi_{1} \\
\Phi_{2}
\end{array}\right)\left(\begin{array}{c}
\Delta y_{t-1}^{2} \\
\Delta y_{t-1}^{1}
\end{array}\right)\left(\begin{array}{l}
\varepsilon_{1 t} \\
\varepsilon_{2 t}
\end{array}\right),
$$


with no deterministic terms to simplify the notations and where the errors are i.i.d. Gaussian with zero mean and variance matrix

$$
\Omega=\left(\begin{array}{cc}
\sigma_{1}^{2} & \sigma_{12} \\
\sigma_{21} & \sigma_{2}^{2}
\end{array}\right)
$$

Vectors $\alpha$ and $\beta$ are respectively $2 \times 1$ loading and cointegrating vectors; short-run dynamic matrices $\Phi_{1}$ and $\Phi_{2}$ are of dimension $1 \times 2$. If the final release $\Delta y_{t}^{2}$ can be treated as weakly exogenous, i.e., $\alpha_{1}=0$, valid inference in the OBS VECM can proceed in the conditional model of $\Delta y_{t}^{1}$ given $\Delta y_{t}^{2}$ and the past, i.e., the second equation of the VECM becomes

$$
\Delta y_{t}^{1}=\lambda \Delta y_{t}^{2}+\alpha_{2}\left(y_{t-1}^{2}-y_{t-1}^{1}\right)+\tilde{\Phi}_{2}\left(\begin{array}{c}
\Delta y_{t-1}^{2} \\
\Delta y_{t-1}^{1}
\end{array}\right)+\tilde{\varepsilon}_{2 t}
$$

where $\lambda=\sigma_{21} / \sigma_{1}^{2}, \tilde{\Phi}_{2}=\Phi_{2}-\lambda \Phi_{1}$ is a $1 \times 2$ vector and $\tilde{\varepsilon}_{2 t}=\varepsilon_{2 t}-\lambda \varepsilon_{1 t}$, see Johansen (1995, Chapter 8). This equation can be interpreted as a 'noise' equation, because the final release enters as regressor in the equation of the first release. If this requirement holds, i.e., the hypothesis $\alpha_{1}=0$ is not rejected, the noise null hypothesis $H_{0}: \lambda=1$ can be investigated.

Analogously, we can rearrange the bivariate VECM as a news equation if the first release is weakly exogenous, i.e., $\alpha_{2}=0$. The 'news' equation becomes

$$
\Delta y_{t}^{2}=\mu \Delta y_{t}^{1}+\alpha_{1}\left(y_{t-1}^{2}-y_{t-1}^{1}\right)+\tilde{\Phi}_{1}\left(\begin{array}{c}
\Delta y_{t-1}^{2} \\
\Delta y_{t-1}^{1}
\end{array}\right)+\tilde{\varepsilon}_{1 t}
$$

where $\mu=\sigma_{12} / \sigma_{2}^{2}, \tilde{\Phi}_{1}=\Phi_{1}-\mu \Phi_{2}$ and $\tilde{\varepsilon}_{1 t}=\varepsilon_{1 t}-\mu \varepsilon_{2 t}$, and if the null hypothesis that $\alpha_{2}=0$ is not rejected, we can test the news null hypothesis $H_{0}: \mu=1$. 


\subsection{Impulse-indicator saturation}

From the previous subsection it emerged that the hypothesis

$$
\alpha_{1}=0 \text { or } \alpha_{2}=0 \text {, }
$$

i.e., that the loading coefficients are zero, is crucial in our setting. From the outcome of those tests we determine the news/noise prevalence of the revision process, although additional restrictions on coefficients have to be tested. By construction however, the diagonals of the OBS in its VECM representation are going to be affected by the presence of outliers due to benchmark revisions, the modification of base dates and redefinitions of the data, updated seasonal factors, etc.

It is not possible - and often not even feasible - without a very good understanding of the series under study and without an insider knowledge of the exact effect of the revision process to rebase the entire series at each vintage dates before constructing the diagonals. The presence of such aberrant values that one creates in the diagonals are going to seriously affect the behavior of our test statistics of the $\alpha \mathrm{s}$.

There exist several ways (either parametric or non-parametric) to identify and to robustify a regression for the presence of such outliers. In this paper we rely on the recent literature on IIS (see Castle, Doornik, and Hendry, 2008; Santos, Hendry and Johansen, 2008; Johansen and Nielsen, 2009; Ericsson and Kamin, 2009; Ericsson and Reisman, 2012). IIS involves adding an indicator dummy variable for each observation to the model. In the simplest case, namely a regression for the $I(0)$ univariate time series $\Delta y_{t}$ without any additional explanatory variables nor step dummies this leads to

$$
\Delta y_{t}=\delta_{0}+\delta_{1} I_{1}+\delta_{2} I_{2}+\ldots+\delta_{T} I_{T}+u_{t}
$$


a model with $T+1$ parameters for $T$ observations (and more generally a model with $T+K$ parameters for $T$ observations), which cannot be estimated.

However, in the essence of the IIS approach the dummies can be added in blocks. In general IIS splits the sample in blocks of $T / 2$ observations each and adds an impulse dummy for every observation in that block of $T / 2$ observations; significant outcomes for a chosen significance level, say 5\%, are retained. Then one drops that set of impulse indicators and proceeds similarly on the other half of the sample, with the significant outcomes retained. Finally one combines the recorded impulse indicators obtained in both parts and those that remain significant when both dummies from both parts are added, are selected. This procedure is implemented in Autometrics (Doornik and Hendry, 2013), where the algorithm makes it possible to estimate such a model, performing a joint selection over dummy variables and other regressors.

We apply this approach to VECM systems for $\left(\Delta y_{t}^{i}, \Delta y_{t}^{i+l}\right)$ and compare the selection of the parsimonious systems with and without IIS.

\section{Illustration}

We consider the Real Gross National Product (GNPC96) series, seasonally adjusted, from the Federal Reserve Bank of St. Louis ALFRED (Archival Federal Reserve Economic Data) data base. The advantage of this indicator of economic activity for the U.S. is that it is available quarterly since 1947Q1 with recorded vintages starting in 1958, a feature not shared by the GDP series. Table 1 shows the different bases of this series.

We do not observe the same number vintages per year. For instance we have a maximum of 12 vintages a year between 1975 and 1991 and about seven or nine since 1992; some years such as 1995 only have five vintages. We clean the data such that we have a nice trapezoid with regular steps. To do so we delete columns 
Table 1: Real GNP: bases and vintages

\begin{tabular}{lll} 
Billions of 1957 Dollars & $1958-12-21$ & $1959-02-18$ \\
Billions of 1954 Dollars & $1959-02-19$ & $1965-08-18$ \\
Billions of 1958 Dollars & $1965-08-19$ & $1976-01-15$ \\
Billions of 1972 Dollars & $1976-01-16$ & $1985-12-19$ \\
Billions of 1982 Dollars & $1985-12-20$ & $1991-12-03$ \\
Billions of 1987 Dollars & $1991-12-04$ & $1996-01-18$ \\
Billions of Chained 1992 Dollars & $1996-01-19$ & $1999-10-28$ \\
Billions of Chained 1996 Dollars & $1999-10-29$ & $2003-12-09$ \\
Billions of Chained 2000 Dollars & $2003-12-10$ & $2009-07-30$ \\
Billions of Chained 2005 Dollars & $2009-07-31$ & Current \\
\hline
\end{tabular}

associated with vintages which are not first releases and when the next observation has the same value. We start the analysis with vintage 1986:04, hence we work with a maximum of $T=108$ quarterly observations. We apply the logarithmic transformation on the data. ${ }^{5}$ Figure 4 displays the first five diagonals corresponding in our case to quarterly vintages. The presence of breaks around the modification of bases is obvious.

We begin with a detailed analysis of the relationship between the first and the second diagonal releases $y_{t}^{1}$ and $y_{t}^{2}$ (OBS1 and OBS2) of U.S. real GNP. We show how the outcomes can be different while using or not the IIS approach. We first assume that the cointegrating vector between them is $(1,-1)^{6}$ and estimate the bivariate VECM models with $z_{t}=y_{t}^{1}-y_{t}^{2}$. We use Autometrics without IIS to determine the lag length and the significance of the loading of each equation in the VECM. The estimation results are presented in equations (6) and (7), along with standard diagnostic tests. Values in (.) correspond to $t$-ratios, whereas values in [.] contain the $p$-values of the corresponding statistics. The results support rejection of $H_{0}: \alpha_{1}=0$ (significance of the first loading) but not $H_{0}: \alpha_{2}=0$, suggesting that

\footnotetext{
${ }^{5}$ We also ran the analyses for levels instead of log levels. Results are available upon request.

${ }^{6}$ Note that this assumption is subsequently tested in Johansen's maximum likelihood context.
} 
Figure 4: First five OBS diagonals

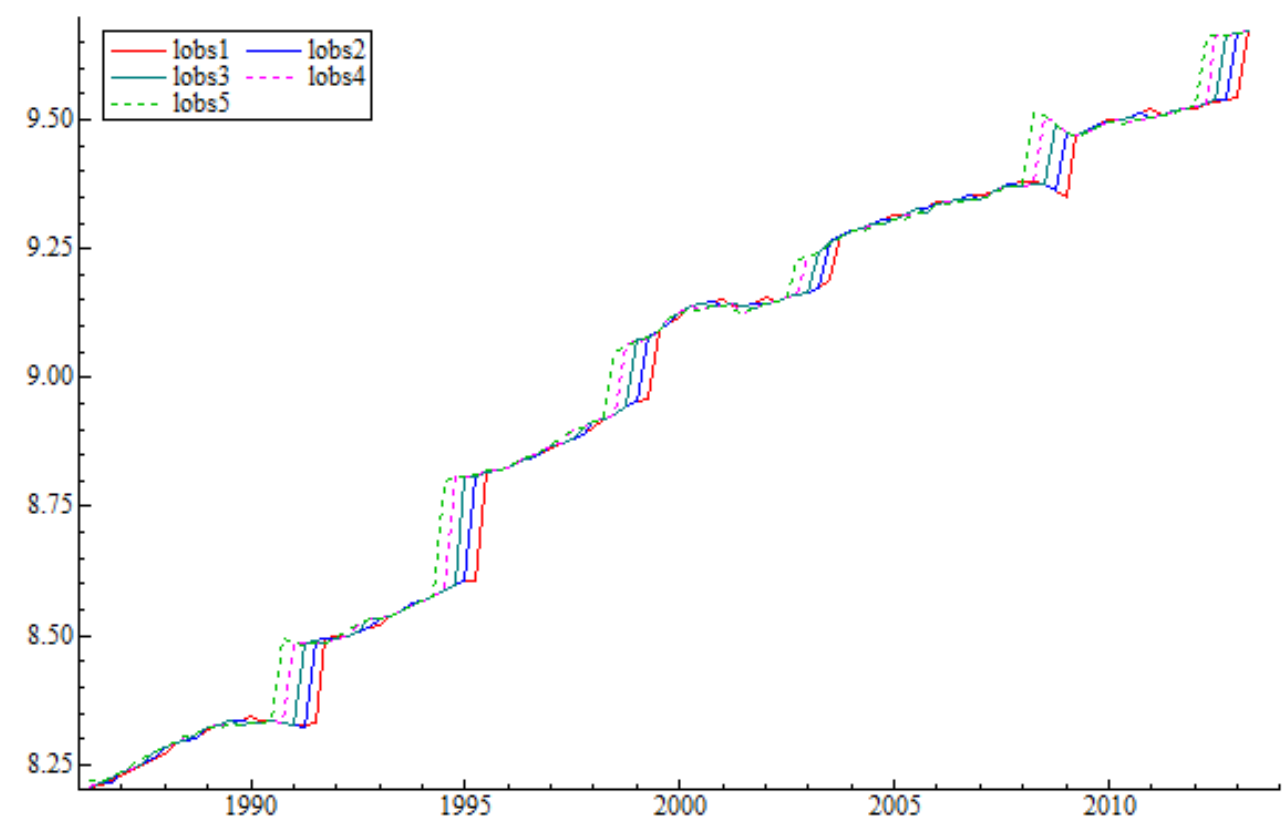

the equation can be used for a noise test.

$$
\begin{aligned}
\Delta y_{t}^{1} & =\underset{(4.14)}{0.0031} \underset{(-6.04)}{0.53} z_{t-1}+\underset{(5.35)}{0.4793 \Delta} y_{t-1}^{2}, \\
R^{2} & =0.98
\end{aligned}
$$

$\operatorname{AR}[1-5]: F(5,94)=0.32109[0.8992] ; \operatorname{ARCH}[1-4]: F(4,94)=2.7953[0.0305]$

Normality: $\chi_{(2)}^{2}=5.4606[0.0652] ; \operatorname{RESET}: F(2,97)=0.54339[0.5825]$

$$
\begin{gathered}
\Delta y_{t}^{2}=\underset{(4.23)}{0.0138}, \\
R^{2}=0.06
\end{gathered}
$$

$\mathrm{AR}[1-5]: F(5,96)=0.25866[0.9345] ; \operatorname{ARCH}[1-4]: F(4,94)=0.19744[0.9391]$

Normality: $\chi_{(2)}^{2}=849.37[0.0000]$ 
The fit of Equation (6) appears to be very good; the $R^{2}$ is about $98 \%$. Moreover the diagnostics of Equation (6) suggest that the equation is well-specified. In contrast, the $R^{2}$ of Equation (7) is strikingly low (6\%) and the normality of the residuals is strongly rejected.

Figures 5 and 6 present the estimated scaled residuals of equations (6) and (7), respectively. The existence of outliers in the second equation of the system is clearly evident and motivates the use of the IIS method.

Figure 5: Scaled residuals of equation (6); Autometrics is used only for the selection of lag length.

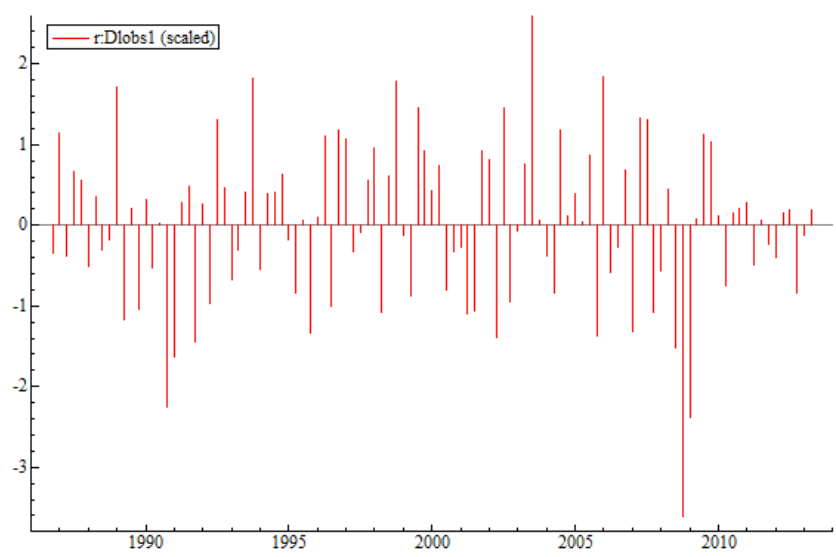

Figure 6: Scaled residuals of equation (7); Autometrics is used only for the selection of lag length.

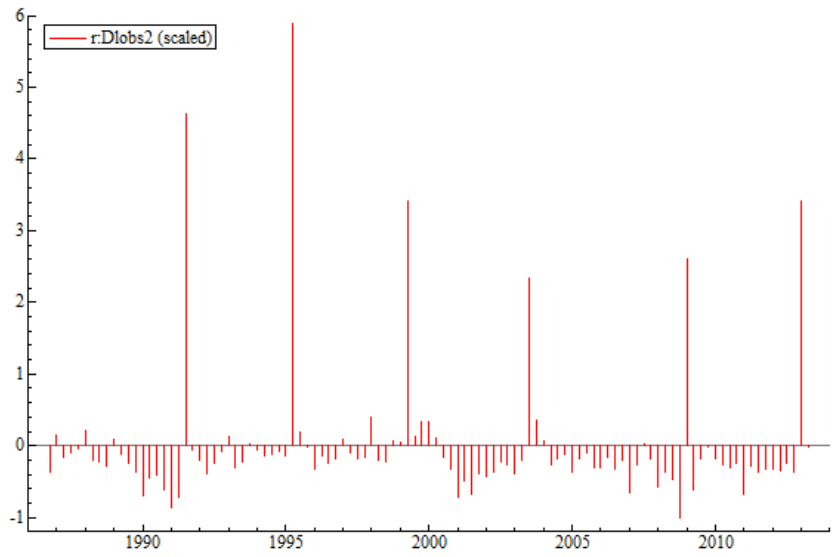


We proceed with estimating the VECM with the use of Autometrics and IIS. The results are presented in equations (8) and (9). Using IIS with a small significance $\operatorname{level}^{7}$ of $1 \%$, we identify 5 dummies in the estimated equation for $\Delta y_{t}^{1}$ (1990:Q4, 1991:Q1, 2003:Q3, 2008:Q4, 2009:Q1) and 7 dummies for $\Delta y_{t}^{2}$ (1991:Q3, 1995:Q2, 1998:Q1, 1999:Q2, 2003:Q3, 2009:Q1, 2013:Q1). It emerges that those dummies do not necessarily match the modifications of the base year given in Table 1 .

$$
\begin{aligned}
& \Delta y_{t}^{1}=\underset{(7.41)}{0.0051} \underset{(-9.45)}{-0.76} z_{t-1}+\underset{(2.95)}{0.24223 \Delta} y_{t-1}^{2}+5 \text { dummies, } \\
& R^{2}=0.98 \\
& \operatorname{AR}[1-5]: F(5,89)=1.0607[0.3876] ; \operatorname{ARCH}[1-4]: F(4,94)=0.27051[0.8963] \\
& \text { Normality: } \chi_{(2)}^{2}=1.8832[0.3900] \text {; RESET: } F(2,92)=1.4489[0.2401] \\
& \Delta y_{t}^{2}=\underset{(9.58)}{0.72} z_{t-1}+\underset{(10.3)}{0.75} \Delta y_{t-1}^{2}+7 \text { dummies, } \\
& R^{2}=0.97 \\
& \mathrm{AR}[1-5]: F(5,88)=0.95033[0.4528] ; \operatorname{ARCH}[1-4]: F(4,94)=0.50713[0.7306] \\
& \text { Normality: } \chi_{(2)}^{2}=1.6992[0.4276] \text {; RESET: } F(2,91)=0.72979[0.4848]
\end{aligned}
$$

The introduction of the IIS substantially improves the estimation results of the VECM, as there is much less evidence of misspecification. The $R^{2}$ for the $\Delta y_{t}^{2}$ rises from $6 \%$ to $97 \%$ with the use of IIS. Figures 7 and 8 which present the estimated residuals of equations (8) and (9) respectively, do not give any evidence of outliers. It is obvious that the use of IIS has greatly improved the statistical adequacy of the model. However, inference regarding the hypotheses of interest changes: both hypotheses $\alpha_{1}=0$ and $\alpha_{2}=0$ are rejected which implies that the bivariate VECM for releases one and two can neither be rearranged as a purely noise equation nor as a purely news equation.

\footnotetext{
${ }^{7}$ A higher significance level (such as $5 \%$ ) yields a much higher number of significant dummies, resulting in a severe reduction in degrees of freedom of each equation.
} 
Figure 7: Scaled residuals of equation (8) with both Autometrics and IIS for the detection of outliers.

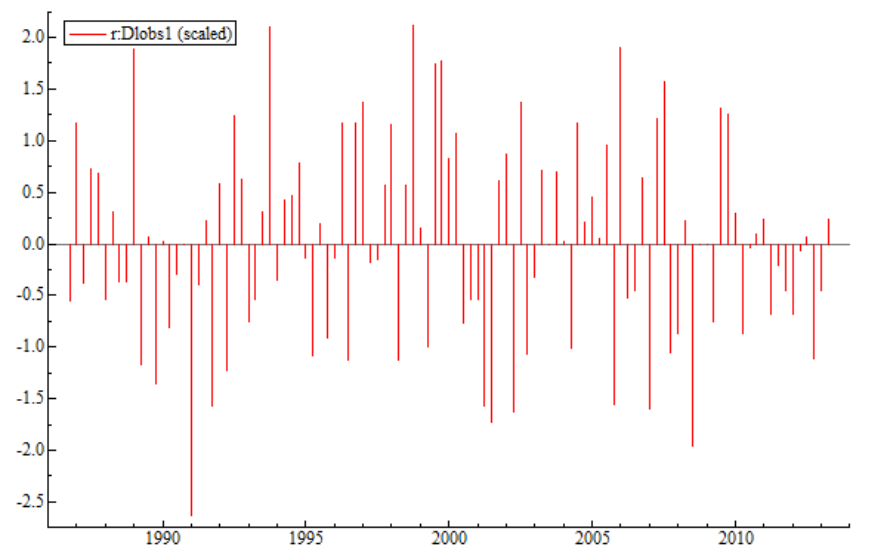

Figure 8: Scaled residuals of equation (9) with both Autometrics and IIS for the detection of outliers

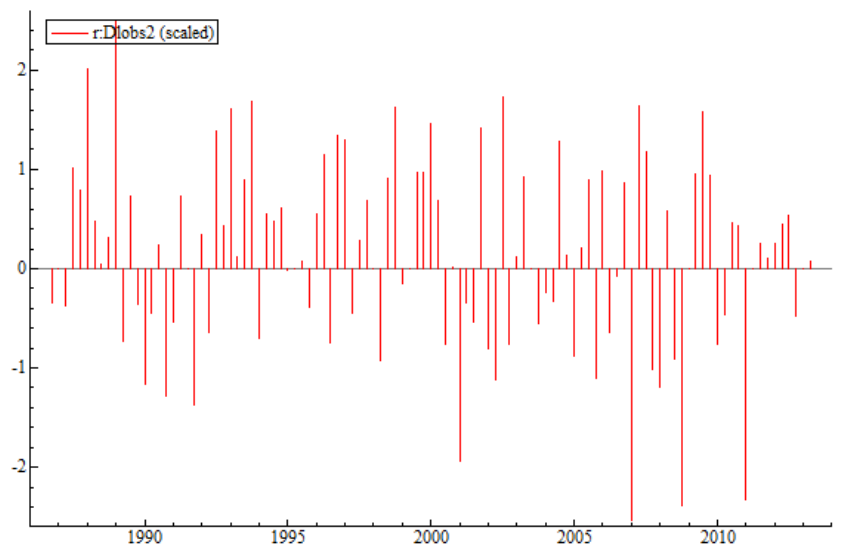


Next we perform the same analysis for all possible combinations of the five releases that we have considered in this illustration. In each case the lag length of the VECMs and the significance of the loadings is determined by Autometrics. We run the estimation of each combination, with and without IIS in order to see the effect of this method to the inference. Table 2 displays the VECM results for the growth rates of the real gross national product, the cointegrating vectors being fixed to $(1,-1)$ for the logs of the variables. Note that the first row of Table 2 reproduces the outcome of the detailed analysis on the first two releases (given in Equations (6)-(9)). An entry with a $0 *$ denotes that the cointegrating vector has not been included by the algorithm in the final model using Autometrics. This is a specification for which either $\alpha_{1}=0$ or $\alpha_{2}=0$ is not rejected.

We observe that the use of the IIS method for the detection of the outliers is crucial for the inference regarding news-noise tests. In the absence of this method we would (falsely) conclude that there is strong evidence for the case of noise, as in all cases the second loading appears to be insignificant. Allowing for the existence of outliers allows us to test for noise only in three cases $\left(y_{t}^{1}, y_{t}^{5}\right),\left(y_{t}^{2}, y_{t}^{4}\right)$ and $\left(y_{t}^{2}, y_{t}^{5}\right)$.

Table 2 also presents the number of outliers detected for each of the equations (8) and (9) by the IIS method. It all cases the number of outliers is higher for Equation (9).

We use the union of the impulse dummy variables given in Table 3 to run the Johansen approach which allows us to estimate (and test) the cointegrating relationship for each of the pairs considered. The results are presented in Table 4. We observe that the estimated (with the Johansen approach) cointegrating relationship is very close to $(1,-1)$ and the estimates of the loadings are very close to the ones resulting from the VECM for known cointegrating vectors. 


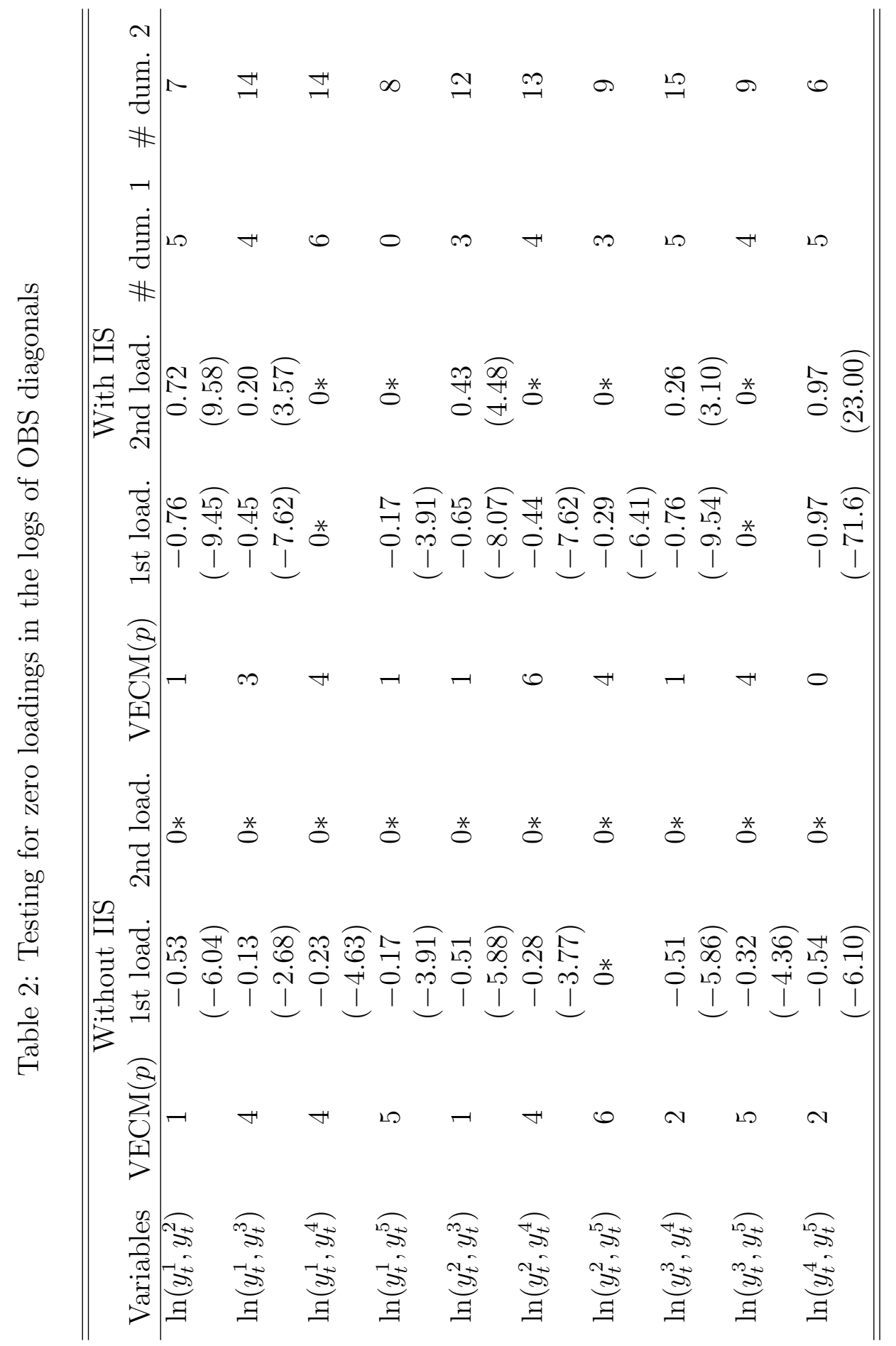




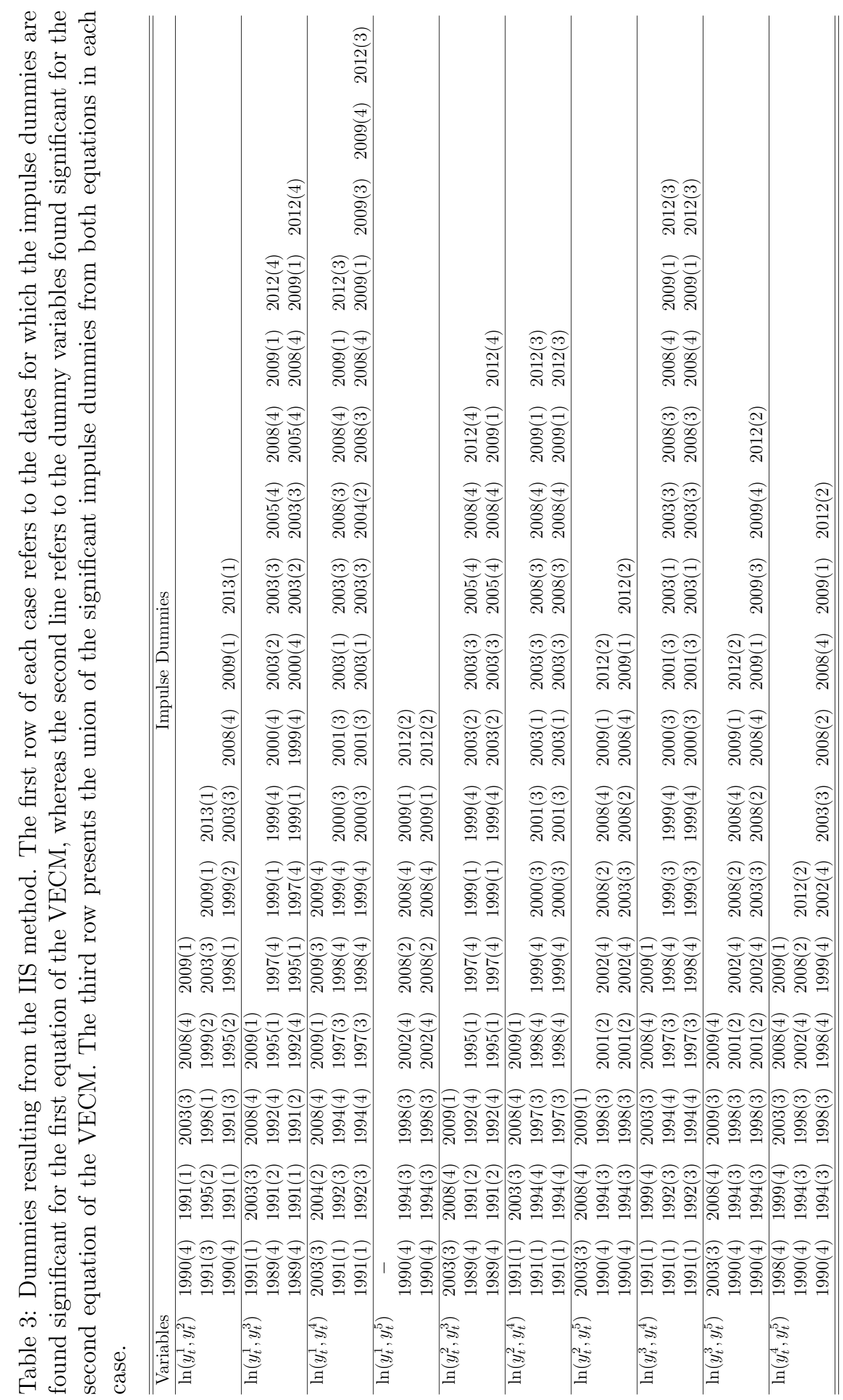




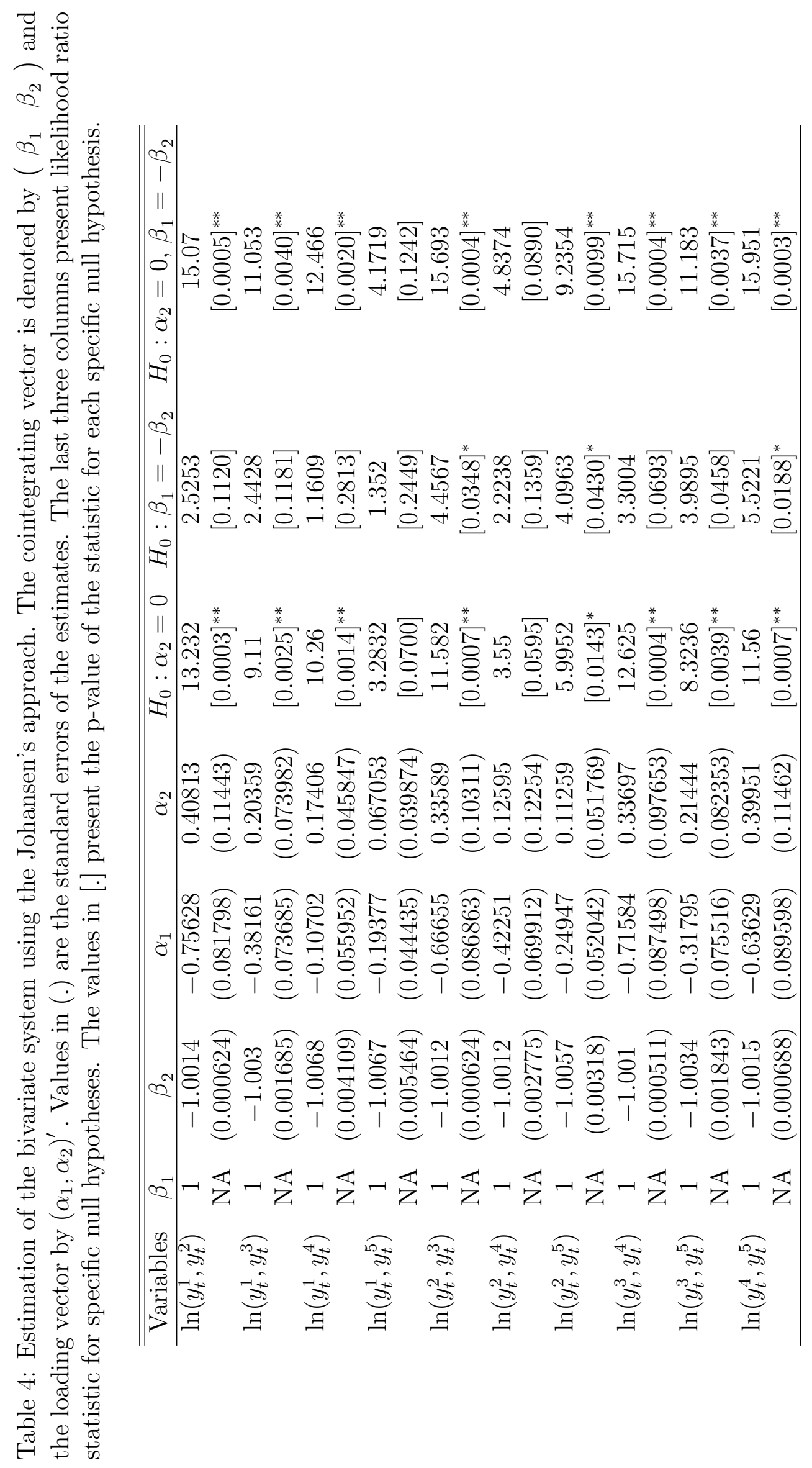


In the context of the Johansen maximum likelihood approach we test the following hypotheses

1. the cointegrating vector is $(1,-1)$,

2. the 2nd loading is equal to zero,

3. the above two restrictions are jointly true.

The null hypothesis $(\lambda=1)$ tests for noise. We run the test for noise for the three cases $\left(y_{t}^{1}, y_{t}^{5}\right),\left(y_{t}^{2}, y_{t}^{4}\right)$ and $\left(y_{t}^{2}, y_{t}^{5}\right)$. The results are presented in Table 5 and suggest that only one combination of variables $\left(y_{t}^{2}, y_{t}^{4}\right)$ can be expressed as a noise equation.

Table 5: Noise tests: We run regression (5) for the purposes of estimating $\lambda$ and testing the null hypothesis that $\lambda=1$. Values in (.) present the standard error of each estimate.

\begin{tabular}{ccccc} 
Variables & $\operatorname{VECM}(p)$ & $\widehat{\lambda}$ & t-test for $H_{0}: \lambda=1$ & \# dum. \\
\hline $\ln \left(y_{t}^{1}, y_{t}^{5}\right)$ & 5 & $\begin{array}{c}0.0151961 \\
(0.01300)\end{array}$ & -75.754 & 25 \\
$\ln \left(y_{t}^{2}, y_{t}^{4}\right)$ & 4 & $\begin{array}{c}0.98621 \\
(0.05626)\end{array}$ & -0.24511 & 19 \\
$\ln \left(y_{t}^{2}, y_{t}^{5}\right)$ & 6 & $\begin{array}{c}-0.00850291 \\
(0.01154)\end{array}$ & -85.918 & 20 \\
& & & \\
\hline
\end{tabular}

\section{Conclusion}

This paper considers news-noise testing of univariate non-stationary real-time series. Standard Mincer-Zarnowitz tests are typically used for stationary time series. We describe an alternative for which we have to test for weak exogeneity in so-called observation based cointegrated systems. If the first release is weakly exogenous, we can condition on it to set up a news equation. Alternatively, if the final release is weakly exogenous, a noise equation can be obtained.

Real-time data suffer from historical revisions, i.e., roughly once every five years redefinitions, methodological innovations affect a data vintage from the beginning 
to the end, which hampers modeling and testing. Rather than taking growth rates or 'cleaning' the data as a first step of the empirical analysis, we propose to employ the IIS approach in our regressions, which involves adding indicator dummies for each observation to the model, and a general-to-specific selection process to test equations down to the preferred specification.

Our illustration with the U.S. real Gross National Product series from ALFRED shows that if we do not include indicator dummies, there is some evidence that we can rearrange the first two GNP releases as a noise equation. However, allowing for historical revisions by means of indicator dummies implies that generally we cannot cast our cointegrated systems into news or noise equations. This conclusion not only holds for the first two releases but also for pairs among the first five releases. Finally, taking logs reduces the number of observational dummies in the final specifications, mitigating the impact of historical revisions to some extent, but not completely. 


\section{Acknowledgements}

This paper was partly written during visits of the first two authors to the University of Bath. The article has benefited from comments received following presentations of previous versions at the Inaugural Society for Economic Measurement Conference, Chicago, the 16th OxMetrics User Conference, Aix-Marseille University, Aixen-Provence, France and the 9th International Conference on Computational and Financial Econometrics (CFE2015), London. In particular we would like to thank Neil Ericsson and Jean-Pierre Urbain for useful comments. The usual disclaimer applies. 


\section{References}

Aruoba, S.B. (2008), "Data revisions are not well behaved", Journal of Money, Credit and Banking, 40, 319-340.

Castle, J.L., J.A. Doornik, and D.F. Hendry (2012), "Model selection when there are multiple breaks", Journal of Econometrics, 169, 239-246.

Clements, M. and A.B. Galvão (2013), "Real-time forecasting of inflation and output growth with autoregressive models in the presence of data revisions", Journal of Applied Econometrics, 28, 458-477.

Croushore, D. (2011a), "Frontiers of real-time analysis", Journal of Economic Literature, 49, 72-100.

Croushore, D. (2011b), "Forecasting with real-time data vintages", in M.P. Clements and D.F. Hendry, editors, The Oxford Handbook of Economic Forecasting, Oxford University Press, Oxford, New York, etc., chapter 9, 247-267.

Cunningham, A., J. Eklund, C. Jeffery, G. Kapetanios, and V. Labhard (2012), "A state space approach to extracting the signal from uncertain data", Journal of Business \& Economic Statistics, 30, 173-180.

De Jong, P. (1987), "Rational economic data revisions", Journal of Business \&6 Economic Statistics, 5, 539-548.

Doornik, J.A. and D.F. Hendry (2013), Empirical Econometric Modelling-PcGiveTM 14: Volume I, Timberlake Consultants Press, London.

Ericsson, N.R. and S.B. Kamin (2009), "Constructive data mining: Modelling argentine broad money demand", in J.L. Castle and N. Shephard, editors, The Methodology and Practice of Econometrics: A Festschrift in Honour of David F. Hendry, Oxford University Press, Oxford, chapter 17, 412-439.

Ericsson, N.R. and E.L. Reisman (2012), "Evaluating a Global Vector Autoregression for forecasting", International Advances in Economic Research, 8, 247-258. 
Faust, J., J.H. Rogers, and J.H. Wright (2005), "News and noise in G-7 GDP announcements", Journal of Money, Credit and Banking, 37, 403-419.

Fixler, D.J. and J. Nalewaik (2009), "News, noise, and estimates of the True unobserved state of the economy", Mimeo, U.S. Bureau of Economic Analysis.

Garratt, A., K. Lee, E. Mise, and K. Shields (2008), "Real time representations of the output gap", Review of Economics and Statistics, 90, 792-804.

Garratt, A., K. Lee, E. Mise, and K. Shields (2009), "Real time representations of the UK output gap in the presence of model uncertainty", International Journal of Forecasting, 25, 81-102.

Gonzalo, J. and C.W.J. Granger (1995), "Estimation of common long-memory components in cointegrated systems", Journal of Business $\&$ Economics Statistics, 13, 27-35.

Götz, T., A. Hecq, and J.-P. Urbain (2016), "Combining forecasts from successive data vintages: An application to U.S. growth", International Journal of Forecasting, 32, 61-74.

Hecq, A. and J.P.A.M. Jacobs (2009), "On the VAR-VECM representation of Real Time data", Mimeo, University of Maastricht.

Hendry, D.F. and J.A. Doornik (2014), Empirical Model Discovery and Theory Evaluation. Automatic Selection Methods in Econometrics, MIT Press, Cambridge MA.

Hendry, D.F. and C. Santos (2005), "Regression models with data-based indicator variables", Oxford Bulletin of Economics and Statistics, 67, 571-595.

Jacobs, J.P.A.M and S. van Norden (2015), "Why are initial estimates of productivity growth so unreliable?", Journal of Macroeconomics [forthcoming]. 
Jacobs, J.P.A.M and Simon van Norden (2011), "Modeling data revisions: Measurement error and dynamics of "true" values", Journal of Econometrics, 161, $101-109$

Johansen, S. (1995), Likelihood-based inference in cointegrated vector autoregressive models, Oxford University Press, Oxford.

Johansen, S. and B. Nielsen (2009), "Saturation by indicators in regression models", in J.L. Castle and N. Shephard, editors, The Methodology and Practice of Econometrics. A Festschrift in Honour of David F. Hendry, Oxford University Press, Oxford, New York, chapter 1.

Kishor, N.K. and E.F. Koenig (2012), "VAR estimation and forecasting when data are subject to revision", Journal of Business \& Economic Statistics, 30, 181-190.

Knetsch, T.A. and H.-E. Reimers (2009), "Dealing with benchmark revisions in real-time data: The case of German production and orders statistics", Oxford Bulletin of Economics and Statistics, 71, 209-235.

Mankiw, N.G., D.E. Runkle, and M.D. Shapiro (1984), "Are preliminary announcements of the money stock rational forecasts?", Journal of Monetary Economics, $14,15-27$.

Mankiw, N.G. and M.D. Shapiro (1986), "News or noise: An analysis of GNP revisions", Survey of Current Business, 66, 20-25.

Mincer, J. and V. Zarnowitz (1969), "The evaluation of economic forecasts", in J. Mincer, editor, Economic Forecasts and Expectations: Analyses of Forecasting Behavior and Performance, National Bureau of Economic Research, New York, chapter $1,3-46$.

Orphanides, A. and S. van Norden (2002), "The unreliability of output gap estimates in real time", Review of Economics and Statistics, 84, 569-583. 
Patterson, K.D. (2000), "Which vintage of data to use when there are multiple vintages of data? cointegration, weak exogeneity and common factors", Economics Letters, 69, 115-121.

Patterson, K.D. (2002a), "Modelling the data measurement process for the index of production", Journal of the Royal Statistical Society, Series A, 165, 279-296.

Patterson, K.D. (2003), "Exploiting information in vintages of time-series data", International Journal of Forecasting, 19, 177-197.

Patton, A.J. and A. Timmermann (2011), "Predictability of output growth and inflation: A multi-horizon survey approach", Journal of Business \& Economic Statistics, 29, 397-410.

Santos, C., D. F. Hendry, and S. Johansen (2008), "Automatic selection of indicators in a fully saturated regression", Computational Statistics, 23, 317-335.

Swanson, N.R. and D. van Dijk (2006), "Are statistical reporting agencies getting it right? Data rationality and business cycle asymmetry", Journal of Business 63 Economic Statistics, 24, 24-42.

Urbain, J.-P. (1992), "On weak exogeneity in error correction models", Oxford Bulletin of Economics and Statistics, 54, 187-207.

Urbain, J.-P. (1995), "Partial versus full system modelling of cointegrated systemsan empirical illustration", Journal of Econometrics, 69, 177-210. 